SPECIAL ISSUE: ARTICLE

Lab and Field Experiments

\title{
Job stress and mental health among social workers: evidence from a field experiment at a public employment support institution in Japan
}

\author{
Yumi Ishikawa $^{1} \cdot$ Miki Kohara $^{1} \cdot$ Aya Nushimoto $^{2}$
}

Received: 14 May 2021 / Revised: 12 August 2021 / Accepted: 12 September 2021 /

Published online: 11 October 2021

(c) The Author(s) 2021

\begin{abstract}
This study examines the causal effects of job stress on workers' mental health. Evaluating the causal relationship between job stress and workers' mental health is challenging due to an endogeneity problem, as heavy workloads and thus job stress are likely assigned to workers in good mental health condition. Endogeneity can also be problematic due to workers' unobserved heterogeneity, such as personal capacities and stress resistance, which are associated with both job stress and mental health outcomes. To solve this problem, we conduct a field experiment at a public employment support institution in Japan. In the experiment, we randomly assign counsellors to jobseekers who are visiting the institution for the first time. Since jobseekers experience varying levels of difficulty finding work, this random assignment results in unexpected workloads, adding job stress for counsellors. We then collect counsellors' daily records on mental health conditions for 4 consecutive weeks, matching the responses with the random assignment data on job counselling. Utilising a panel structure of the dataset and applying a fixed-effects model, we remove counsellors' time-invariant unobserved heterogeneities. We measure counsellors' mental health in terms of both subjective, self-reported perceptions and objective aspects of blood pressure and pulse. The results reveal that the job stress driven by newly assigned problematic jobseekers deteriorates aspects of counsellors' objective mental health, whereas it does not appear to affect their subjective mental health. This result suggests that workers can accumulate the negative effects of job stress on mental health that they may be unaware of.
\end{abstract}

Keywords Job stress · Mental health · Counsellor · Field experiment · Daily panel · RCT

Yumi Ishikawa

y-ishikawa@osipp.osaka-u.ac.jp

1 Osaka School of International Public Policy, Osaka University, Osaka, Japan

2 Hiroshima Shudo University, Hiroshima, Japan 


\section{JEL Classification $\cdot$ C93 $\cdot$ J81 $\cdot 118$}

\section{Introduction}

Mental health problems are one of the leading causes of disability worldwide. The global cost of mental health problems is estimated to be approximately $\$ 2.5$ trillion per year in poor health and reduced productivity (The Lancet Global Health, 2020). The burden of mental health problems affects both individual patients and also society.

For most of us, work is a significant aspect in our lives. Working conditions can serve as important determinants of workers' mental health. The relationship between working conditions and workers' mental health has been explored in a number of studies. Most of these studies find that poor working conditions, such as high job burden (e.g., Cottini \& Lucifora, 2013; Oshio et al., 2018), long working hours (e.g., Sato et al., 2020), low decision authority (Cottini \& Lucifora, 2013; Hanson et al., 2009), and poor interpersonal relationships in the workplace (e.g., Hanson et al., 2009; Kuroda \& Yamamoto, 2018; Oshio et al., 2018), deteriorate workers' mental health. On the other hand, some studies show that working conditions, such as decision authority (Oshio et al., 2018) and interpersonal relationships (Cottini \& Lucifora, 2013), have no significant effects on workers' mental health.

Some jobs pose a higher risk due to the nature of the work. Careers in human services, such as counsellors in job-matching institutions, have been recognised as an occupation that faces high occupational stress. However, existing studies present competing evidence on how working condition affects human service professionals' mental health. Several early studies suggest that working in human services deteriorates workers' mental health (Adams et al., 2008; Conrad \& Kellar-Guenther, 2006; Craig \& Sprang, 2010; Giordano et al., 2021). This is because the hours devoted to listening to clients' distress can be stressful for workers (Fligey, 1995). In contrast, other studies suggest that working in human services improves workers' perceptions of compassion satisfaction and therefore improves mental health outcomes (Conrad \& Kellar-Guenther, 2006; Sodeke-Gregson et al., 2013).

Motivated by these mixed empirical results, this study re-examines the potential causal effect of workloads and job stress on workers' mental health, focusing on job counsellors' workplace. A re-examination of causal impact is important for research to bring new findings focusing on gaining insights into real causality. It also offers important implications advocating the advancement of the welfare of human service workers and the inherent need for stress-relief policies and devices.

There are two challenges in causal examinations. The first challenge is the existence of an endogeneity problem. In a real workplace, heavy workloads and thus job stress are likely assigned to counsellors in good mental health condition. It is also possible that counsellors' time-invariant factors, such as counsellors' personal capacities and stress resistance, are associated with both job stress and mental health outcomes. However, only a few studies consider this problem of endogeneity when examining the effect of working conditions on human service professionals' mental health. 
This study conducts a field experiment at a public employment support institution in Japan. In the experiment, we randomly assign counsellors to jobseekers, with varying levels of difficulty in finding a job, who are making their first counselling appointment. In this way, we can assess the effect of randomised counsellors' workloads and job stress led by job seekers on counsellors' mental health. To address the remaining possibility of endogeneity problem, we also collect counsellors' daily records on mental health for 4 consecutive weeks, constructing a daily panel data set and applying a counsellor's fixed-effects model. This is an approach taken by several researchers in the previous literature to control for individual time-invariant factors producing an endogeneity problem (Kuroda \& Yamamoto, 2018; Oshio et al., 2018; Sato et al., 2020).

Another challenge is the existence of a measurement error problem when engaging mental health indicators. Measuring the precise condition of individual mental health is customarily a difficult challenge. A growing amount of research discusses problems of ambiguity in subjective indicators of health outcomes (Bago d'Uva et al., 2008; Burgard \& Chen, 2014; Johnston et al., 2009; Moullan \& Jusot, 2014). However, objective indicators are hardly obtained particularly in real workplaces. A few studies employ objective indicators.

This study successfully collects counsellors' records on objective mental health measures of two biomarkers of stress: blood pressure and pulse. These indicators are used as general biomarkers of stress in the existing studies (Mani et al., 2013; Perrewé et al., 2004; Steptoe \& Wardle, 2005). These biomarkers are used as objective indicators of mental health in addition to subjective indicator measured by selfreported perceptions of mental health. It must be noted here that several other objective mental health indicators are used in medical studies, such as saliva components (e.g., Holleman et al., 2012); however, it is not possible to collect these indicators every day in a real work environment. Blood pressure and pulse are used as feasible and ideal objective indicators for this empirical investigation.

Our findings first indicate that job stress exerts no significant effect on subjective mental health. In contrast, job stress is demonstrated to indeed affect objective mental health for counsellors. The increase in job stress induced by jobseekers with difficulties in finding a job deteriorates objective mental health for counsellors who manage difficult cases. Note that these findings are obtained after randomising counsellors' job stress and controlling for counsellors' observed and unobserved heterogeneities. We conclude that there is a real causal effect of job stress at least in terms of the objective mental health of counsellors.

This study contributes to the literature in multiple ways. First, conducting a field experiment in a real workplace makes it possible to assign counsellors a random shock of workloads and job stress. Second, information on counsellors' mental health after work is merged with information on jobseekers' difficulties prior to counselling. The latter information is also unknown to counsellors prior to the counselling. This makes it possible to assess the effect of unexpected objective job burdens on counsellors' mental health following the counselling. Third, we collect a daily record of counsellors' mental health, making it possible to conduct fixedeffects estimation, controlling for counsellors' time-invariant characteristics. Fourth, this study measures mental health using blood pressure and pulse as objective 
indicators along with survey questionnaire responses as subjective indicator. Our results compensate for the existing studies using only subjective indicators of mental health. Finally, this study focuses on human service professionals' mental health, which has largely been ignored for a long time, partly because they are professionals working in a field that encounters mental health problems. The rising occurrence of mental illness among the workers in professional fields and their absence from work has become serious issues. Our results add new approaches and empirical insights to the existing literature.

\section{Methodologies}

\subsection{Hypotheses}

Our research question is whether job stress really affects mental health in the case of job counsellors. Specific hypotheses to be tested are: (1) job stress induced through workloads affect counsellors' mental health conditions and (2) such effects are found even in the case using objective health measures. The latter hypothesis is tested to verify the former hypothesis for a more accurate definition of mental health, as suggested in the previous literature (Bago d'Uva et al., 2008; Burgard \& Chen, 2014; Johnston et al., 2009; Moullan \& Jusot, 2014).

There is an important note in hypothesis testing. As mentioned in the previous section, we seek to capture a true causal effect of job stress on mental health. To do this, a field experiment is conducted in which different workloads are assigned to randomly selected counsellors. We also elaborate the empirical estimations, using a daily panel data set of counsellors' mental health survey responses. As such, we try to remove unobserved heterogeneities in health conditions through a fixed-effects model. The next two subsections will explain the details.

Regarding the methodology applied to capture causality, the measures of counsellors' objective mental health conditions are also contributed to identify a true causality. This is because a reporting bias can be diminished using objective rather than subjective measures (Johnston et al., 2009). Each counsellor's objective mental health condition was recorded around the same time every day over 4 consecutive weeks to answer the second hypothesis, which is beneficial to our causal examination.

\subsection{A field experiment}

As mentioned in the introduction, a field experiment took place at a public employment support institution in Japan. We conducted this experiment from 4 March 2019 to 29 March 2019. ${ }^{1}$ This institution provides various services that aid jobseekers

\footnotetext{
${ }^{1}$ We conducted a 2-week long pilot experiment prior to the main experiment. The research team supervised the jobseekers' survey and counsellor's daily panel record, checking all answers and records to ensure that the prepared survey questionnaires are suitable for the context and identifying items that are likely to lead to errors or misunderstandings.
} 
with finding work without charge. These include the provision of job information, seminars, and personal counselling.

In the experiment, counsellors are randomly assigned to jobseekers with differing levels of difficulty in finding work. It is not feasible to assign workloads randomly to workers in a real workplace, wherein we know that some workloads are hard enough. Workers would feel unfairly treated if they were assigned to difficult work, and employers would not agree to conduct such a treatment. At the same time, employers tend to assign difficult tasks to capable workers with sufficient skills and experience to achieve better job-matching outcomes. In such a situation, our experiment assigning counsellors randomly to jobseekers with difficulties obtaining jobs is one of the possible methods to ensure a random assignment of workloads to counsellors. We generated random numbers on a counsellors' work allocation schedule and asked the counselling organiser to place the counsellor in the order of the generated numbers when jobseekers made a counselling appointment.

Note here that this random assignment is conducted only for jobseekers who are visiting the institution for the first time. That is, only the first counselling session is the target of our experiment to capture a 'shock' but not an expected workload for counsellors. If a jobseeker has visited the institution before, counsellors might know their difficulties with finding work, and may be able to predict how challenging the counselling would be prior to the counselling. In this case, the counsellor's mental health may not properly react to a given workload. Limiting the experiment to the first counselling session is also realistic, in a sense that a random assignment to repeaters is almost impossible, since repeaters usually have preferred counsellors and individually make appointments with them.

\subsection{Two surveys}

\subsubsection{Job stress measured in jobseekers' survey}

To grasp counsellors' workloads, we measure jobseekers' difficulties with finding work. Workloads are defined as heavy and cause counsellors job stress if they encounter jobseekers with difficulties finding work. There are two notes on this measure of job stress. First, we conduct a survey on jobseekers but not counsellors. This is to capture the objective burden of counselling but not the subjective burden which a counsellor feels. Second, we conduct this survey before the first counselling, not through counsellors or anyone in the institution, but through hired disinterested members. This is because we should capture the level of jobseekers' difficulty with finding work before the counselling, and because jobseekers can answer honestly without any pressure from counsellors.

Jobseekers are asked about difficulties of findings work and their motivation for job searching, as well as personal characteristics. This cross-sectional survey includes 131 jobseekers. Supposing that counsellors need more energy to work with jobseekers with a lot of anxiety about finding work or those who are less-motivated, we use high level of anxiety of job finding and insufficient levels of motivation for job search as proxies for job stress driven by jobseekers. 


\subsubsection{Mental health conditions measured in counsellor's daily panel record}

Our focal outcome variables are counsellors' mental health. They were answered by counsellors every day around the same time at the end of daily duty. Counsellors were asked about their own mental health conditions, while being asked to measure and record their blood pressure and pulse at the same time. They were also asked about working conditions, such as interpersonal relationships, working hours, tasks other than counselling, and other general conditions. The sample questionnaire of this daily record is presented in the Appendix.

\subsection{Target samples of counsellors in the public job-matching institution}

The target is the counsellors in an existing public institution in Osaka, the second largest city of Japan. All of them are specialists who have qualifications of counselling. The target counsellors in this experiment are all females and most of them are in their $50 \mathrm{~s}$. They usually work from 8:30 in the morning till 5:30 in the evening usually for $8 \mathrm{~h}$ a day during 5 weekdays. Counsellors have obligations to do tasks other than counselling, such as meeting and duty outside of the institution. These other tasks are allocated evenly to all the counsellors. Thus, there are no selection problems to be chosen to engage in the first-time counselling.

The jobseekers who visit this job-matching institution have similar characteristics. Many of them are relatively young in $20 \mathrm{~s}$ and $30 \mathrm{~s}$, looking for regular jobs but not for casual work. The proportion of jobseekers who are women is uniform $50 \%$. Most of them have previous work experiences and, in many cases, their job search period is less than 3 months.

Counsellors' health records are taken every day, but jobseekers' survey are conducted only when the first-time counselling is offered. Thus, the total number of the observations, which contains matched records of counsellors' health with jobseekers' survey, becomes 107 . This is unbalanced daily panel of 13 counsellors over 4 weeks: about 6.9 counsellors' records are matched with jobseekers' survey. During this sampling period, there were no special news or events affecting the labor market.

\subsection{Estimation models}

To identify the effect of job stress on counsellors' mental health, we estimate the following model:

$$
\mathrm{MH}_{i t}=\beta_{0}+\beta_{1} \mathrm{JS}_{i t}+\mathrm{X}_{i t}^{\prime} \beta+\mu_{i}+\lambda_{t}+\varepsilon_{i t},
$$

where $\mathrm{MH}_{i t}$ denotes the mental health condition of counsellor $\mathrm{i}$ on day $\mathrm{t}$ and $\mathrm{JS}_{i t}$ denotes job stress driven by jobseekers. $X_{i t}^{\prime}$ is a vector of additional control variables. These are job characteristics and work environment, including interpersonal relationships in the workplace, hours of work, and tasks. Other daily characteristics such as stress in private life and hours of sleep are also included. Finally, $\mu_{i}$ denotes a counsellor's fixed effect, $\lambda_{t}$ denotes time fixed-effects, and $\varepsilon_{i t}$ denotes a 
counsellor-specific error term. We use robust standard errors which are robust to autocorrelation and heteroskedasticity. We first show the results controlling only for time effects common to all individuals and then present the results controlling for job characteristics, work environment, and life characteristics.

We expect $\beta_{1}$ to be positive if heavy job stress leads to poor mental health. A negative coefficient could also be possible if heavy job stress results in improving counsellors' job satisfaction and therefore improving their mental health. This is particularly possible in cases using subjective indicator of mental health, since subjective health indicators possibly reflect a temporal change in a feeling of excitement. For example, it is often answered as 'mentally healthy' when we had a sense of achievement even if we had a negative effect of stressful environment in a physical sense. In contrast, the negative coefficient might not be found in the case using objective health indicators, since they indicate physical reactions to the stress but not mistaken feelings about the exposure to that.

\subsubsection{Mental health}

This study captures counsellors' mental health as subjective and objective indicators. Subjective mental health is measured through a mental health-related questionnaire in the counsellors' daily health records. The questionnaire asks which of eight moods are true for them that day. The eight moods include irritated, anxiety, restless, depression, sick, careless, sleepy, and unmotivated. For each mood, the response is measured by five categories ranging from 1 (not at all) to 5 (very much). The answers form a mental health score ranging from 8 to 40. For the estimation, we transform this into $Z$-score, taking the standard deviation as well as the mean into account to measure goodness/badness of mental health. Objective mental health is measured with two biomarkers of stress: blood pressure and pulse. At the counsellors' workplace, we set up the Omron Fully Automatic Digital Blood Pressure Monitor (model: HEM-1021). Using the devise, counsellors can simply check their two biomarkers in a few minutes when they leave off work. Measuring blood pressure and pulse is not a big burden on counsellors, so that we can mitigate a possibility of panel attrition by a large cost of recording. Objective mental health measured using blood pressure is a dummy variable, indicating that a counsellor has high blood pressure. This variable equals 1 if the systolic blood pressure is $\geq 140 \mathrm{mmHg}$ or the diastolic blood pressure is $\geq 90 \mathrm{mmHg}$ and 0 otherwise. Objective mental health is also measured by pulse through the number of beats per minute (bpm). The scales of mental health indicate that higher values denote worse mental health conditions.

\subsubsection{Job stress induced by jobseekers during counselling}

Based on frequently reported ground-level complaints in the field of counselling, we suppose that counsellors likely have more pressure and burden when they counsel the jobseekers who are worried too much about outcomes of job-matching and less-motivated to find jobs. We use high level of anxiety about job finding and insufficient levels of motivation for job search as proxies for job stress driven by jobseekers. 
The scale of anxiety based on the question in the jobseekers' survey, 'Are you worried about whether you will be able to find a job'? The responses are measured by four categories ranging from 1 (not at all) to 4 (very much). We then create a daily dummy variable indicating a high stress day when jobseekers who received first-time counselling services at the institution have high levels of anxiety about job findings. Specifically, this variable equals 1 if $80 \%$ or over among all the jobseekers who took the first-time job counselling in a day answer 3 (anxious about the job findings) or 4 (very anxious), and 0 otherwise.

The scale of insufficient levels of motivation is based on the question in the jobseekers' survey, 'How soon do you want to start working'? The response is measured in months. This is a minimum length jobseekers can wait/reserve, and the longer length means less-motivation to find jobs. We create daily average of this minimum reservation length as an indicator of insufficient levels of motivation among jobseekers who took the first-time counselling in a day.

We assign these two daily indicators of the number of 'difficult' jobseekers to the counsellors who engaged in the first-time counselling on the day. That is, job stress measured by jobseekers' anxiety takes 1 if the counsellors engaged in the first-time counselling and encountered anxious jobseekers, and 0 if they did not engaged in the counselling or engaged but did not meet anxious jobseekers. Job stress measured by jobseekers' insufficient motivation takes larger values if the counsellor provided the first-time counselling to less-motivated jobseekers, and smaller values if the counsellor encountered motivated jobseekers. For the counsellors who did not provide first-time counselling in the day, the average values of the reservation months are allocated, which considered that they did not meet either less-motivated or moremotivated jobseekers. ${ }^{2}$ Thus, the scales of job stress indicate that higher values denote higher job stress.

\subsubsection{Other controls}

Although our RCT allows us to estimate the effect without any control variables, we additionally show the case with other covariates. These include job characteristics and work environment. The scale of work relationship is based on the question in the counsellors' survey, 'Is there a positive ambience at the workplace today'? The responses are measured by four categories ranging from 1 (not at all) to 4 (very much). There is a possibility that counsellors with poor mental health are more likely to report worse work relationship than counsellors with good mental health. To address this potential endogeneity problem, this study creates a daily average value of work relationship among counsellors. Hours of work are measured in hours.

\footnotetext{
${ }^{2}$ We also applied different definitions of job stress. For example, we allocated the minimum value of jobseekers' reservation periods for the measure of insufficient motivation. The main implications shown in the next section are unaltered at all. We also tried to use jobseekers' difficulties from their characteristics such as the number of jobs they changed before the unemployment and the previous job information. However, we gave up using such information to identify difficult jobseekers, because our sample jobseekers are rather similar and no sufficient differentials.
} 
Counselling, outside duty, and meeting are dummy variables, equal to 1 if the counsellor has the task and 0 otherwise.

Stress in private life is also included to capture difficulty in a general life outside of the workplace. This is based on the question in the counsellors' survey,'Did you feel stress in your private life yesterday after work or this morning'? The responses are measured by five categories ranging from 1 (not at all) to 5 (very much). Hours of sleep, measured in hours, are also included to capture physical health conditions.

As for macro (daily) changes common to all the counsellors, we include week fixed-effects and day-of-week fixed effect. Survey week is a linear time trend consisting of the week number during the survey period. Monday and Friday are dummy variables that capture the influence specific to the day-of-week. We also include a rainy-day dummy taking 1 if the survey day is rainy and 0 otherwise. The control of these macro-aspects is quite important, since there seem to be dropped factors affecting both counsellors and jobseekers in errors in Eq. (1).

The summary statistics of all variables used in our estimation are presented in Table 1. A balancing test reported in Table 5 shows that most of the control characteristics are indifferent between higher and lower levels of job stress driven by the randomly assigned jobseekers. Note, however, that some variables such as tasktypes and day-characteristics may be different between the two. Therefore, we will show the results with and without controlling for them in the next section.

There are two notable points prior to presenting results. First, even if we controlled for the above-mentioned factors, omitted variables remain in the error term. We apply a fixed-effects model in the estimation to remove individual's unobserved factors from the error term as long as they are time-invariant. Second, the estimation with lots of covariates might suffer from an over-control problem, although wellfitted specifications are selected for our estimation. This point is especially emphasised considering that we conduct RCT and apply the fixed-effects model. The results without covariates can be better in such a case. The results will be carefully interpreted.

\section{Results}

\subsection{Main results}

Table 2, 3 presents the main result of the fixed-effects model with daily panel records. Table 2 is the case using the subjective measures of mental health conditions. Our main explanatory variables are the job stress each counsellor might feel in the first-time counselling for jobseekers. Columns (1) and (2) measure this as jobseekers' level of anxiety for finding work, whereas (3) and (4) measure this as jobseekers' level of less-motivation for finding work. In each measure, Columns (1) and (3) show the results controlling only for time (daily) effects common to all individuals, whereas Columns (2) and (4) show the results controlling for the observed individual characteristics, on job characteristics and their lives.

According to column (1), the coefficient on counsellors' job stress given by jobseekers' anxiety is negative but insignificant, at least at $10 \%$ significance level. Job 
Table 1 Summary statistics

\begin{tabular}{|c|c|c|c|c|c|c|}
\hline & Observations & Number of id & Mean & Std. dev & Min & $\operatorname{Max}$ \\
\hline \multicolumn{7}{|l|}{ Dependent variables $^{\mathrm{a}}$} \\
\hline Subjective mental health & 107 & 13 & 0.023 & 0.953 & -1.755 & 2.190 \\
\hline \multicolumn{7}{|l|}{ Objective mental health } \\
\hline High blood pressure & 107 & 13 & 0.327 & 0.471 & 0 & 1 \\
\hline Pulse & 107 & 13 & 68.654 & 11.442 & 45 & 107 \\
\hline \multicolumn{7}{|l|}{ Independent variables } \\
\hline \multicolumn{7}{|c|}{ Job stress driven by jobseekers whom a couonsellor encountered ${ }^{b}$} \\
\hline Jobseekers' anxiety & 107 & 13 & 0.383 & 0.488 & 0 & 1 \\
\hline Jobseekers' less-motivation & 107 & 13 & 2.878 & 1.795 & 0 & 7.8 \\
\hline \multicolumn{7}{|c|}{ Couonsellor's job and daily life characteristics } \\
\hline Work relationship $^{c}$ & 107 & 13 & 3.290 & 0.121 & 3 & 3.667 \\
\hline Hours of work & 107 & 13 & 8.171 & 0.674 & 3 & 9.833 \\
\hline \multicolumn{7}{|l|}{ Task } \\
\hline Counselling & 107 & 13 & 0.841 & 0.367 & 0 & 1 \\
\hline Outside duty & 107 & 13 & 0.019 & 0.136 & 0 & 1 \\
\hline Meeting & 107 & 13 & 0.355 & 0.481 & 0 & 1 \\
\hline Stress in private life ${ }^{d}$ & 107 & 13 & 1.832 & 1.041 & 1 & 5 \\
\hline Hours of sleep & 107 & 13 & 6.344 & 1.110 & 4 & 9 \\
\hline \multicolumn{7}{|l|}{ Day characteristics } \\
\hline Survey week & 107 & 13 & 4.187 & 1.125 & 3 & 6 \\
\hline \multicolumn{7}{|l|}{ Day of the week } \\
\hline Monday & 107 & 13 & 0.308 & 0.464 & 0 & 1 \\
\hline Friday & 107 & 13 & 0.252 & 0.436 & 0 & 1 \\
\hline Rainy day or not & 107 & 13 & 0.271 & 0.447 & 0 & 1 \\
\hline
\end{tabular}

${ }^{a}$ Worse mental health outcomes are associated with higher values

${ }^{\mathrm{b}}$ Heavier stress is associated with higher value

${ }^{c}$ Better interpersonal relationships in the workplace are associated with higher value

${ }^{\mathrm{d}}$ More stress is associated with higher value

stress does not seem to affect counsellors' subjective mental health. The same result is also found in column (2), wherein individual job and life characteristics as well as time-varying effects and unobserved individual fixed-effects are controlled for.

Although similar results are obtained in the case when counsellors' stress level is measured by jobseekers' less-motivation in columns (3) and (4), the negative effect is significant at a $5 \%$ significance level in the case without covariates on individual characteristics. As explained in the model section, a negative coefficient is possible. This means that job stress raises individual subjective mental health. That is, job stress can be an engine for our work. Counsellors who met with troublesome cases or difficult jobseekers with less-motivation for job-seeking may feel excitement to accomplish the task. This is particularly possible in the case using subjective mental health, since the subjective measure indicates how individual counsellors feel at the 
Table 2 The effects of job stress on subjective mental illness

(1) (2) (3) (4)

\begin{tabular}{|c|c|c|c|c|}
\hline \multicolumn{5}{|c|}{ Job stress measured by jobseekers' } \\
\hline Anxiety & $-0.223(0.139)$ & $-0.225(0.184)$ & & \\
\hline Less-motivation & & & $-0.053^{* *}(0.018)$ & $-0.046(0.027)$ \\
\hline \multicolumn{5}{|c|}{ Counsellors' job and daily life characteristics } \\
\hline \multicolumn{2}{|l|}{ Work relationship } & \multicolumn{2}{|l|}{$-0.169(0.516)$} & $-0.365(0.549)$ \\
\hline \multicolumn{2}{|l|}{ Hours of work } & \multicolumn{2}{|l|}{$0.012(0.028)$} & $-0.012(0.040)$ \\
\hline \multicolumn{5}{|l|}{ Task } \\
\hline \multicolumn{2}{|l|}{ Counselling } & \multicolumn{2}{|l|}{$0.152(0.175)$} & $0.050(0.147)$ \\
\hline \multicolumn{2}{|l|}{ Outside duty } & \multicolumn{2}{|l|}{$1.771 * * *(0.116)$} & $1.743 * * *(0.123)$ \\
\hline \multicolumn{2}{|l|}{ Meeting } & \multicolumn{2}{|l|}{$0.065(0.074)$} & $0.084(0.073)$ \\
\hline \multicolumn{2}{|l|}{ Stress in private life } & \multicolumn{2}{|l|}{$0.097(0.080)$} & $0.095(0.074)$ \\
\hline \multicolumn{2}{|l|}{ Hours of sleep } & \multicolumn{2}{|l|}{$0.050(0.054)$} & $0.033(0.069)$ \\
\hline \multicolumn{5}{|l|}{ Day characteristics } \\
\hline Survey week & $0.003(0.081)$ & $0.042(0.093)$ & $0.003(0.090)$ & $0.047(0.108)$ \\
\hline \multicolumn{5}{|l|}{ Day of the week } \\
\hline Monday & $-0.264 *(0.134)$ & $-0.246(0.147)$ & $-0.312 *(0.150)$ & $-0.338^{*}(0.173)$ \\
\hline Friday & $-0.140(0.151)$ & $-0.032(0.175)$ & $-0.159(0.151)$ & $-0.084(0.207)$ \\
\hline Rainy day or not & $0.049(0.169)$ & $0.189(0.141)$ & $0.012(0.186)$ & $0.190(0.165)$ \\
\hline Constant & $0.197(0.363)$ & $-0.255(2.303)$ & $0.294(0.425)$ & $0.841(2.798)$ \\
\hline Counsellors' fixed effects & Yes & Yes & Yes & Yes \\
\hline Observations & 107 & 107 & 107 & 107 \\
\hline$R$-squared & 0.105 & 0.340 & 0.098 & 0.331 \\
\hline Number of id & 13 & 13 & 13 & 13 \\
\hline
\end{tabular}

Dependent variable: Counsellors' subjective mental health ( $z$-score)

(1) Dependent variables are z-score of counsellors' subjective mental health index

(2) The total number of the observations is 107: unbalanced panel of 13 individuals over the first-time counselling dates in consecutive 4 weeks

(3) Robust standard errors are in parentheses

$* * *, * *$, and $*$ Indicate that the coefficients are significant at $1 \%, 5 \%$, and $10 \%$ level, respectively

end of the workday. Counsellors may feel at least temporary satisfaction and good health, although such temporal excitement may induce bad health for them in the long run. Whether such an excitement or an increase in subjective health leads to future bad health will be discussed later when we present the results using objective health measure.

Table 3 presents the effects of job stress on objective mental health. The first four columns show the results using the index of high blood pressure as a dependent variable [Part (a)]. Columns (1) and (2) are the cases measuring counsellors' job stress against the anxiety level of a jobseeker with whom each counsellor is assigned to conduct first counselling session, whereas columns (3) and (4) are the cases measuring counsellors' stress when counselling less-motivated jobseekers. All the 


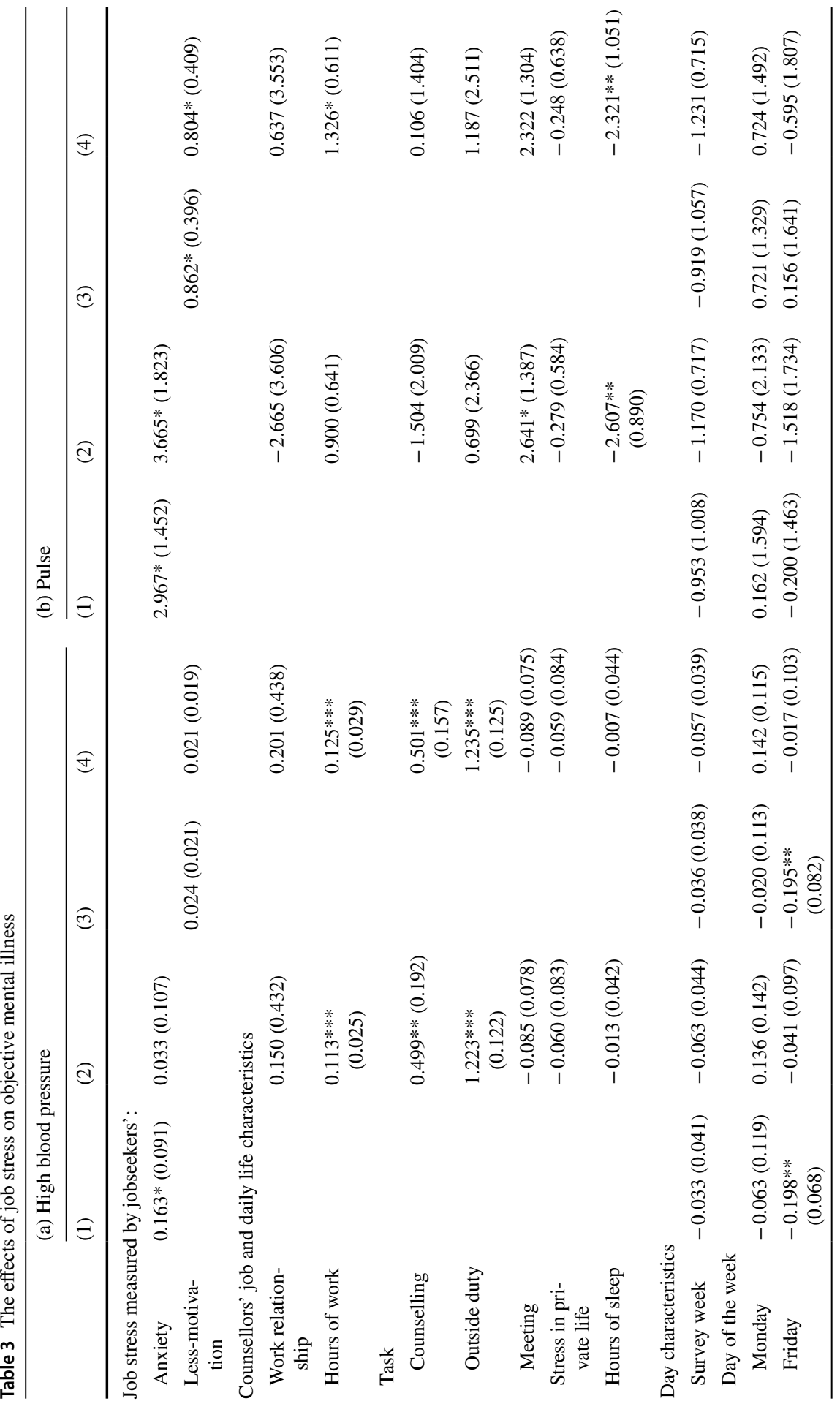




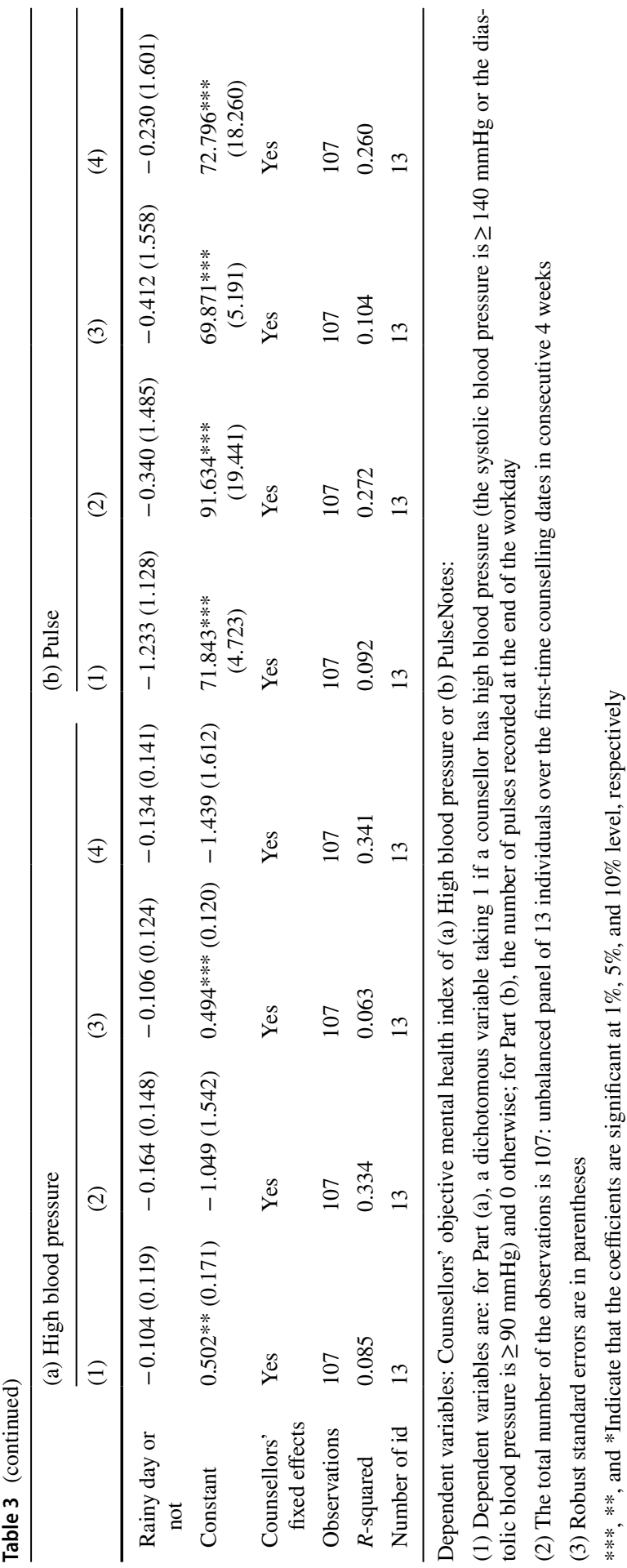




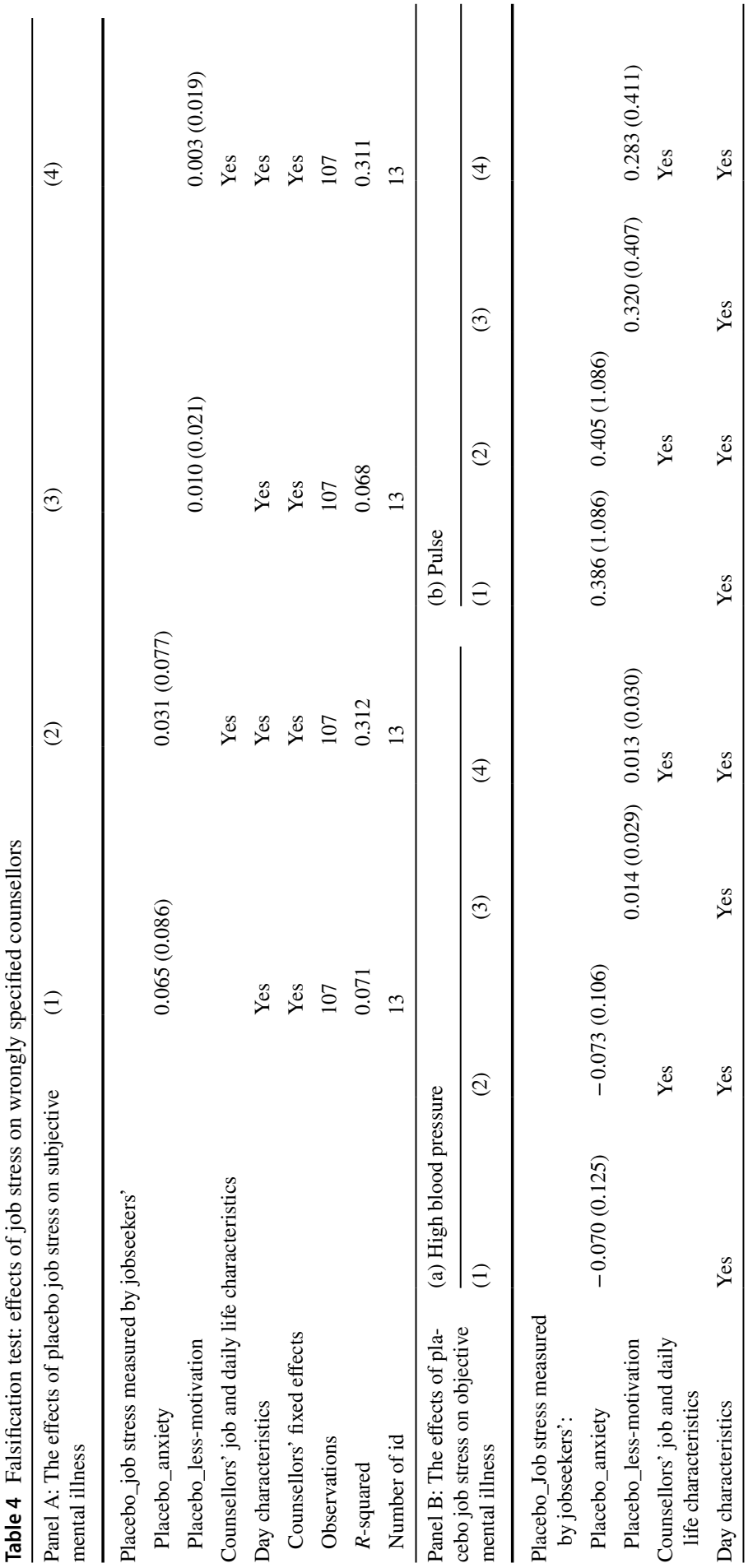




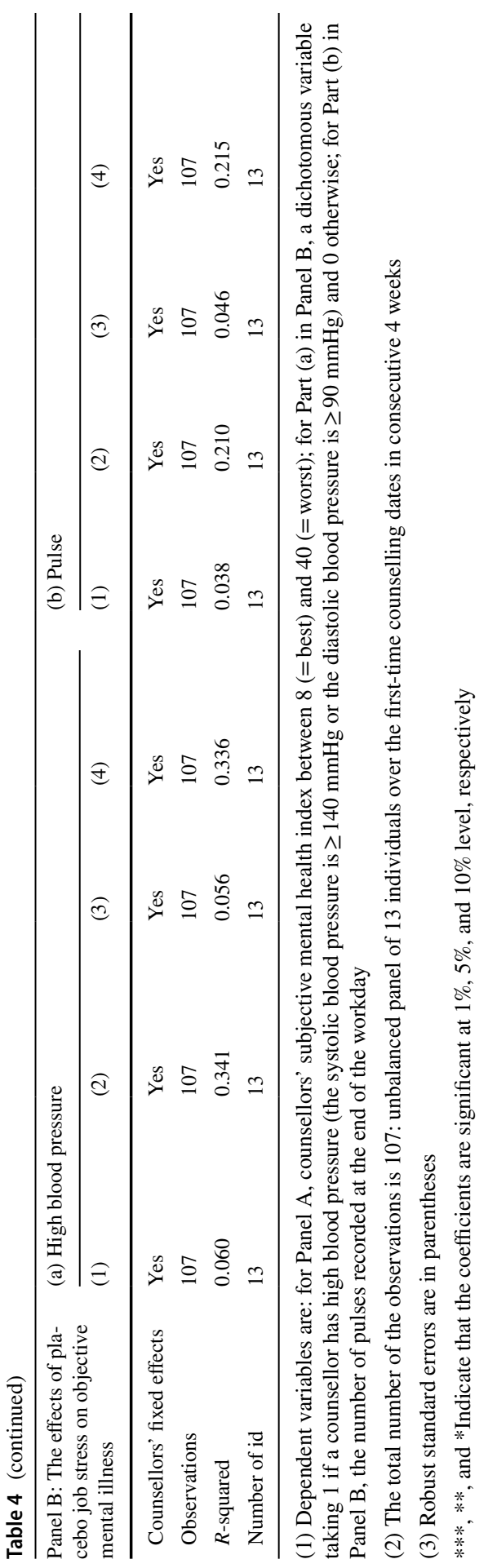


coefficients on job stress are positive and at least significant at a $10 \%$ significance level in the case using job stress driven by jobseekers' anxiety without individual covariates (column a-1), which indicates that job stress possibly leads to high blood pressure. Note that we use a fixed-effects model based on individual's daily health records. That is, the obtained results indicate that an increase in daily job stress can be connected to an increase in the probability of high blood pressure, compared to each individual's average blood pressure condition.

Part (b) in Table 3 presents the results using the index of pulse as a dependent variable. Column definitions are the same as those in Part (a) and Panel A. The coefficients on job stress in either case of anxiety or less-motivation measure with and without individual characteristics are positive and significant at a $10 \%$ significance level. Specifically, counsellors' job stress driven by jobseekers' anxiety and by lessmotivation raises assigned counsellors' probability of high blood pressure and a raised pulse.

Note that these results are found even after controlling for individual characteristics of daily life and job environment and daily changes common to all the people in addition to the counsellors' time-invariant unobserved heterogeneities. Moreover, counsellors are assigned randomly to a jobseeker visiting the institution for the first time to receive initial counselling to find work. Although these jobseekers usually make an appointment prior to their visit, their original information is not available to the counsellors before the first counselling session. Therefore, a counsellor encounters a'troublesome' jobseeker, full of anxiety, and/or less-motivation looking to find work. We can conclude that there is a causal effect of job stress on counsellors' mental health, resulting in an increase of job stress that deteriorates counsellors' mental health.

\subsection{Robustness check}

This section confirms the robustness of the previously obtained results in several ways. First, we conduct a falsification test on random assignments of counsellors matching to jobseekers. To do this, we assigned job stress randomly to those who did not offer the first-time counselling as well as those who truly conducted firsttime counselling. Such a placebo should not show significant effects on counsellors' mental health in any specifications if job stress is a cause to affect counsellors' mental health. The results are presented in Table 4. There are no significant effects of job stress on counsellors' mental health in case of wrongly specifying a treatment group. Thus, we confirm the previous result, indicating that job stress driven by characteristics of jobseekers encountered by a counsellor in an assigned day affects counsellors' mental health, at least in terms of objective measures of mental health.

Second, we assess the effects of panel data attrition on the results obtained. Our data are daily-based panel data following each counsellor for 4 weeks, which may result in a burden of answering questions every day, although all the counsellors understood the purpose of recording their health conditions and that the recording period is fixed to end in 4 weeks. The targeted number of counsellors is 13 , but the there are several observations dropped from the survey in 
the middle of the period. If a certain sample dropped systematically, the regression errors would not become random, making the estimators biased. We first checked whether there are no differentials between dropped and un-dropped groups. $T$ test shows that there are no significant differentials in subjective or objective measures of mental health between dropped and un-dropped counsellors. We next checked whether individual characteristics, including job stress, explain attrition. We regressed a dummy variable, taking 1 if the observation is subject to attrition and 0 otherwise, on the same covariates in the previous tables. We confirmed that neither of the anxiety or less-motivation is significant in the regression (refer to Appendix Table 6).

Third, we adopted different specifications of the estimation, changing the definitions of dependent and independent variables, confirming that the main implication of the results is unaltered. For example, we conducted the regression using the level of subjective mental health scores but not its z-score, and obtained the same result of insignificant effects of job stress on subjective mental health. As another example, we conducted a regression specifying job stress as jobseekers' depth of uncertainty for future employment, finding that it raises a probability of high blood pressure in the case excluding individual and job characteristics.

\section{Discussion}

Our results demonstrate that job stress really worsens counsellors' mental health. This result is apparent when using the objective but not subjective measures of mental health. What does this result mean? This study uses daily panel data to examine the relationship between daily workloads and mental health, examining relatively immediate reactions to workload exposure. Based on a physiological theory, the first phase of stress response is the stimulation of stress hormones. Studies focused on the first phase of the stress response use subjective health measures (e.g., anxiety and emotional exhaustion), stress hormone levels (e.g., cortisol) and daily fluctuations in blood pressure as health indicators. The chronic activation of the first phase reaction can lead to second and third phases, represented by reactions of metabolic, cardiovascular, and immune systems. This study uses subjective health, blood pressure, and pulse, capturing the stress response to daily workloads at the first phase, which can be a risk factor for the next phase.

Why is this effect only found on objective health measures, while many previous studies reveal that work stress is associated with self-reported health? (e.g., Nixon et al., 2011) The main difference between our study and previous studies is its empirical methodology. First, many previous studies use subjective/selfreported health measures and also self-reported measures of work stress (e.g., Hanson et al., 2009; Kuroda \& Yamamoto, 2018; Oshio et al., 2018). In this case, spurious correlation between health and job stress would emerge, since both are answered by the same respondent at the same time. 
The second difference of our research from the previous studies is that our results are based on experiments. We attempted a random assignment of job stress to counsellors, assigning a counsellor to jobseekers attending counselling for the first time. Since some jobseekers have serious difficulties in finding work, while others have rather an easier time obtaining employment, counsellors who are assigned to jobseekers with severe difficulty may have higher job stress. Since counsellors in our experiments have never met the jobseekers or received any information prior to the meeting, the first counselling session can present a negative shock if a counsellor encounters a jobseeker with difficulties. Such a surprise is difficult to be caught in a real workplace, since'burdensome' jobseekers are usually assigned to the most capable counsellors with superior abilities and sufficient experience. That is why, our research presents an important example of a true causal effect of job stress on mental health. Some past experimental studies indicate that the link between job stress and mental health is actually weak. For example, Schaubroeck et al. (1993) reveal that role clarity is not associated with subjective health. Mikkelsen et al. (2010) find that participatory intervention has an impact on work-related stress, but not on general subjective health. Our results are similar to these findings. Using a field experiment in a real workplace setting, we reveal the negative effect of job stress on objective health.

Note that a different result between subjective and objective measures is not a contradiction. Survey responses of subjective health measures do not always correspond to objective health measures. Although some studies find the correlation between self-reported health and objectively measured health, whether subjective indicators represent actual health status remains controversial. The main problem of self-reported health is reporting heterogeneity. Johnston et al. (2009) examine the relationship between income and health, finding that the probability of false negative reporting depends on individual characteristics. Johnston et al. (2009) also reveal a sizeable relationship between income and objective health, but no relationship is found between income and subjective health, implying that self-reported health may underestimate impact. Doiron et al. (2015) examine whether self-reported health is a good predictor of future health, finding that subjective health predicts more serious illnesses better than less serious illnesses. Thus, there is a possibility that objective health measures capture what subjective measures cannot capture. Our results might imply that there are some stressors which individuals do not realise subjectively.

If the last explanation is applied, the obtained results may give a serious warning regarding the relationship between job stress and mental health in the field of counselling. Counsellors may not notice negative shocks on their mental health, although it is apparent that the body can indeed react to such shocks in terms of high blood 
pressure and a rapid pulse. This negative shock can accumulate for counsellors in the long run, which might lead to serious mental illness, drop in productivity, and absence from work. Our results suggest that the existence of job stress in the workplace requires more careful consideration to avoid the sudden onset of mental health problems in the workplace.

\section{Conclusion}

This paper examined a causal relationship between job stress and mental health in a job counselling workplace, conducting a field experiment that designated different workloads and thus job stress to randomly assigned job counsellors in public jobmatching institutions in Japan.

Based on the counsellors' daily records on both subjective and objective mental health matched with the information on jobseekers the counsellor encountered in the course of daily work, we found that job stress induced by jobseekers with difficulties indeed worsens the assigned counsellors' mental health in terms of high blood pressure and rapid pulse, whereas job stress does not appear to affect subjective mental health. The contributions of this study are in its attempt to capture a causal effect of job stress on mental health. The field experiment in an existing job-matching institution and daily panel records on subjective and objective mental health measures make it possible for us to clarify causality. The finding that job stress deteriorates mental health is valuable among the inconsistent results in the existing literature.

Our results suggest that the negative shock on mental health in the workplace can be accumulated on workers, while they are not noticed that. This may lead to lower productivity and/or work absence. It cannot be emphasised enough, considering that the results obtained in the workplace of counsellors who specialise in mental health problems. Job stress must be considered as a factor that can create mental illness for workers and establish workplace solutions to prevent workers from facing mental health problems as a result. 


\section{Appendix}

Appendix I: Counsellors' Health Daily Records

\begin{tabular}{|ll}
\hline Systolic blood pressure: & mmHg \\
Diastolic blood pressure: & mmHg \\
Pulse: $\quad$ bpm &
\end{tabular}

Q1. Please circle the number that is correct for you today.

\begin{tabular}{|c|c|c|c|c|c|}
\hline & not true at all & not very true & neutral & true & very true \\
\hline (1) I am very satisfied with my performance & 1 & 2 & 3 & 4 & 5 \\
\hline (2) I had a very heavy workload & 1 & 2 & 3 & 4 & 5 \\
\hline (3) I could not finish my work & 1 & 2 & 3 & 4 & 5 \\
\hline $\begin{array}{l}\text { (4) (If you had counselling) } \\
\text { Dealing with jobseekers was harder than usual }\end{array}$ & 1 & 2 & 3 & 4 & 5 \\
\hline
\end{tabular}

Q2. Is there a positive ambience at the workplace today?

1. not true at all 2. not very true 3. true 4. very true

Q3. Please circle the number that is correct for you today.

\begin{tabular}{|l|c|c|c|c|c|}
\cline { 2 - 6 } \multicolumn{1}{c|}{} & not true at all & not very true & neutral & true & very true \\
\hline (1) Irritated & 1 & 2 & 3 & 4 & 5 \\
\hline (2) In anxiety & 1 & 2 & 3 & 4 & 5 \\
\hline (3) Restless & 1 & 2 & 3 & 4 & 5 \\
\hline (4) Depressed & 1 & 2 & 3 & 4 & 5 \\
\hline (5) Sick & 1 & 2 & 3 & 4 & 5 \\
\hline (6) Careless & 1 & 2 & 3 & 4 & 5 \\
\hline (7) Sleepy & 1 & 2 & 3 & 4 & 5 \\
\hline (8) Unmotivated & 1 & 2 & 3 & 4 & 5 \\
\hline
\end{tabular}

Q4. Please tick the number that describes your fatigue right now.

Best condition without fatigue

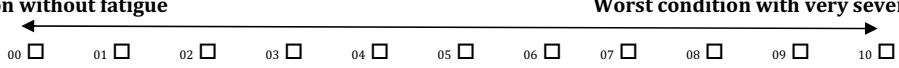

Q5. Did you feel stress in your private life yesterday after work or this morning?

$\begin{array}{llll}\text { 1. not at all 2. not much } & \text { 3. neutral } & \text { 4. a little } \quad 5 \text {. very much }\end{array}$

Q6. How long did you sleep last night? Approximately hours mins

Q7. Please tick all tasks that you engaged in today.

$\square$ new counselling(number of counselling $\square$ follow-up counselling (number of counselling

$\square$ other counselling(in the institution, number of counselling

$\square$ other counselling(outside of the institution, number of counselling

$\square$ conducting a seminar(in the institution) $\square$ conducting a seminar(outside of the institution)

$\square$ participating in a training (in the institution) $\square$ participating in a training(outside of the institution)

$\square$ participating in a meeting (in the institution) $\square$ participating in a meeting(outside of the institution)

$\square$ preparing documents $\square$ other tasks(

See Tables 5 and 6. 


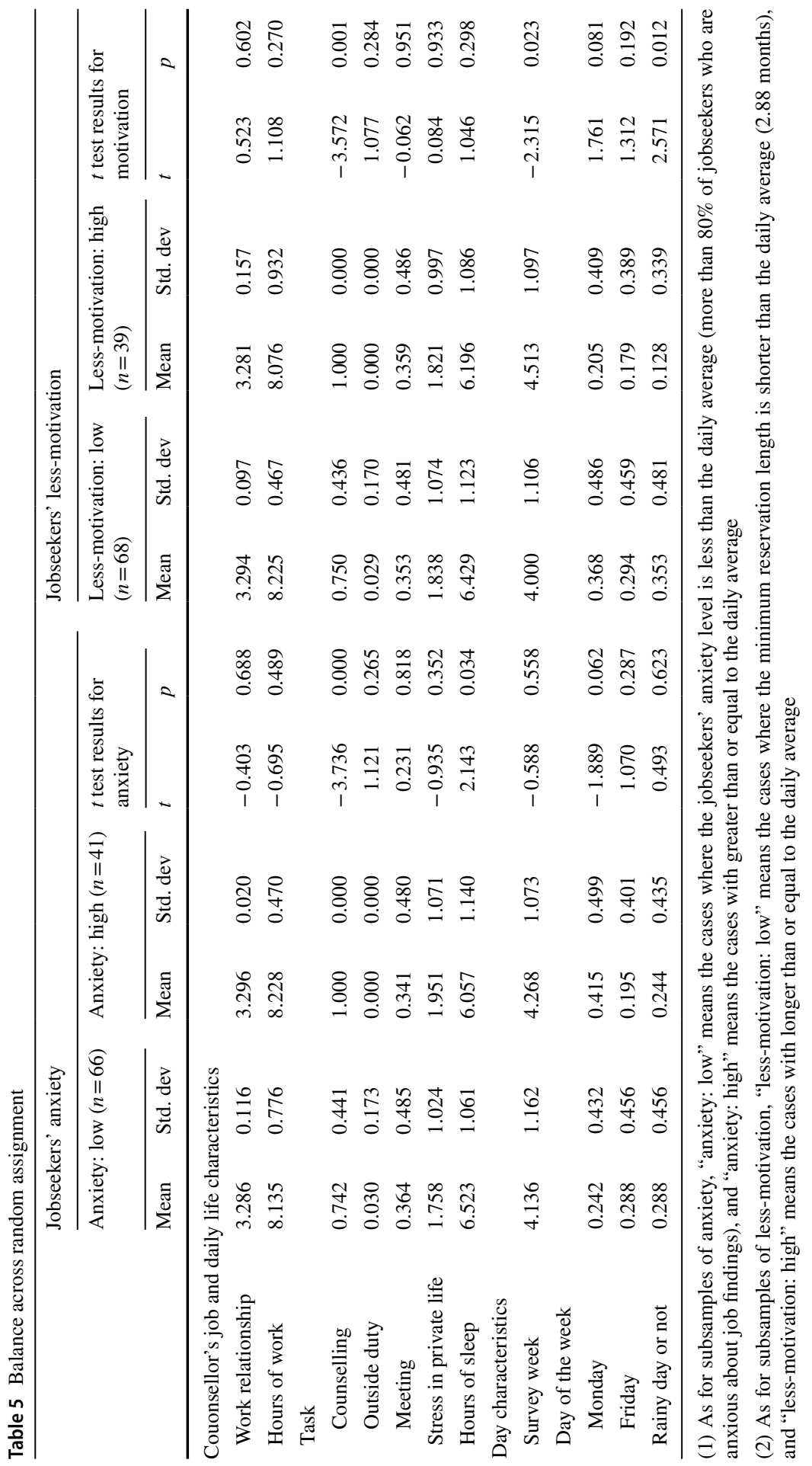


Table 6 Panel data attrition problem

$(1)$

(2)

\begin{tabular}{lll}
\hline $\begin{array}{l}\text { Job stress measured by jobseekers' } \\
\text { Anxiety }\end{array}$ & $-0.122(0.758)$ & \\
$\quad$ Less-motivation & & $-0.046(0.096)$ \\
Counsellors' job and daily life characteristics & $2.468(3.762)$ & $1.100(2.496)$ \\
$\quad$ Work relationship & $-1.417(2.647)$ & $-0.191(1.353)$ \\
Hours of work & & \\
Task & $0.441(0.732)$ & $0.139(0.511)$ \\
$\quad$ Counselling & - & - \\
$\quad$ Outside duty & $-0.821^{*}(0.447)$ & $-0.479(0.315)$ \\
Meeting & $-0.017(0.344)$ & $-0.165(0.452)$ \\
Stress in private life & $-1.031(0.710)$ & $-1.077 *(0.636)$ \\
Hours of sleep & $9.072(15.944)$ & $4.712(11.940)$ \\
Constant & 70 & 70 \\
Observations & 13 & 13 \\
Number of id & -8.915 & -8.984 \\
Log likelihood & 9.27 & 12.17 \\
Wald statistic & &
\end{tabular}

Dependent variables: Attrition dummy variable

Notes (1) A dependent variable is a dummy variable taking 1 if the observation is subject to attrition and 0 otherwise. Probit model is used for this estimation

(2) Robust standard errors are in parentheses

$* * *, * *$ and $*$ Indicate that the coefficients are significant at $1 \%, 5 \%$ and $10 \%$ level, respectively

Acknowledgements We are grateful to the participants of the International Workshop for Lab and Field Experiments (18 March 2021) for many useful comments. We express sincere gratitude to counsellors and jobseekers who participated in the surveys. We also thank the institution for their acceptance of conducting the field experiment at the institution. The second author received grants of JSPS Kakenhi grant number JP18K016490 (Japan Society for the Promotion of Science), and JCER Research Grant 20192021 (Japan Center for Economic Research).

Funding Miki Kohara: JSPS Kakenhi grant number JP18K016490, JCER Research Grant (Japan Center for Economic Research, 2019-2021).

Availability of data and materials The data that support the findings of this study are allowed to use only for the researchers who participated the field experiment conducted under the agreement of the cooperation between Osaka University and Osaka Prefecture. Disclosure of the data is not permitted for anyone in any formant.

Code availability Code for analysis is available upon request.

\section{Declarations}

Conflicts of interest The authors declare none.

Ethics approval Our field experiment was conducted under the agreement of the cooperation between Osaka University and Osaka Prefecture. This allows the authors who belong(ed) to Osaka University to 
conduct the experiments at public job-support institution in Osaka Prefecture without an approval of Ethics committee when the experiment was conducted in 2019. Since we are not allowed to open the information on the location of public institution, the paper does not clarify the name and location of the institution.

Consent to participate We held an explanation session about the participation to our experiment for all the counsellors (our possible participants), and asked a submission of the sheet of agreement. We also allowed them not to participate into the experiment.

Consent for publication Not applicable.

Open Access This article is licensed under a Creative Commons Attribution 4.0 International License, which permits use, sharing, adaptation, distribution and reproduction in any medium or format, as long as you give appropriate credit to the original author(s) and the source, provide a link to the Creative Commons licence, and indicate if changes were made. The images or other third party material in this article are included in the article's Creative Commons licence, unless indicated otherwise in a credit line to the material. If material is not included in the article's Creative Commons licence and your intended use is not permitted by statutory regulation or exceeds the permitted use, you will need to obtain permission directly from the copyright holder. To view a copy of this licence, visit http://creativecommons.org/licen ses/by/4.0/.

\section{References}

Adams, R. E., Figley, C. R., \& Boscarino, J. A. (2008). The compassion fatigue scale: Its use with social workers following urban disaster. Research on Social Work Practice, 18(3), 238-250. https://doi. org/10.1177/1049731507310190

Bago d'Uva, T., Van Doorslaer, E., Lindeboom, M., \& O’Donnell, O. (2008). Does reporting heterogeneity bias the measurement of health disparities? Health Economics, 17, 351-375. https://doi.org/10. 1002/hec.1269

Burgard, S. A., \& Chen, P. V. (2014). Challenges of health measurement in studies of health disparities. Social Science \& Medicine, 106, 143-150. https://doi.org/10.1016/j.socscimed.2014.01.045

Conrad, D., \& Kellar-Guenther, Y. (2006). Compassion fatigue, burnout, and compassion satisfaction among Colorado child protection workers. Child Abuse \& Neglect, 30(10), 1071-1080.

Cottini, E., \& Lucifora, C. (2013). Mental health and working conditions in Europe. ILR Review, 66(4), 958-988. https://doi.org/10.1177/001979391306600409

Craig, C. D., \& Sprang, G. (2010). Compassion satisfaction, compassion fatigue, and burnout in a national sample of trauma treatment therapists. Anxiety, Stress, \& Coping, 23(3), 319-339. https:// doi.org/10.1080/10615800903085818

Doiron, D., Fiebig, D. G., Johar, M., \& Suziedelyte, A. (2015). Does self-assessed health measure health? Applied Economics, 47(2), 180-194. https://doi.org/10.1080/00036846.2014.967382

Fligey, C. R. (1995). Compassion fatigue as secondary traumatic stress disorder an overview. In C. R. Figley (Ed.), Compassion fatigue: Coping with secondary traumatic stress in those who treat the traumatised. Brunner/Mazel.

Giordano, A. L., Gorritz, F. B., Kilpatrick, E. P., Scoffone, C. M., \& Lundeen, L. A. (2021). Examining secondary trauma as a result of clients' reports of discrimination. International Journal for the Advancement of Counselling, 43(1), 19-30. https://doi.org/10.1007/s10447-020-09411-z

Hanson, L. L. M., Theorell, T., Bech, P., Rugulies, R., Burr, H., Hyde, M., Oxenstierna, G., \& Westerlund, H. (2009). Psychosocial working conditions and depressive symptoms among Swedish employees. International Archives of Occupational and Environmental Health, 82(8), 951-960. https://doi.org/10.1007/s00420-009-0406-9

Holleman, M., Vreeburg, S. A., Dekker, J. J., \& Penninx, B. W. (2012). The relationships of working conditions, recent stressors and childhood trauma with salivary cortisol levels. Psychoneuroendocrinology, 37(6), 801-809. https://doi.org/10.1016/j.psyneuen.2011.09.012

Johnston, D. W., Propper, C., \& Shields, M. A. (2009). Comparing subjective and objective measures of health: Evidence from hypertension for the income/health gradient. Journal of Health Economics, 28(3), 540-552. https://doi.org/10.1016/j.jhealeco.2009.02.010 
Kuroda, S., \& Yamamoto, I. (2018). Good boss, bad boss, workers' mental health and productivity: Evidence from Japan. Japan and the World Economy, 48, 106-118. https://doi.org/10.1016/j.japwor. 2018.08.002

Mani, A., Mullainathan, S., Shafir, E., \& Zhao, J. (2013). Poverty impedes cognitive function. Science, 341(6149), 976-980. https://doi.org/10.1126/science.1238041

Mikkelsen, A., Saksvik, P. O., \& Landsbergis, P. (2010). The impact of a participatory organizational intervention on job stress in community health care institutions. Work \& Stress, 14(2), 156-170. https://doi.org/10.1080/026783700750051667

Moullan, Y., \& Jusot, F. (2014). Why is the 'healthy immigrant effect' different between European countries? European Journal of Public Health, 24, 80-86. https://doi.org/10.1093/eurpub/cku112

Nixon, E. A., Mazzola, J. J., Bauer, J., Krueger, J. R., \& Spector, P. E. (2011). Can work make you sick? A meta-analysis of the relationships between job stressors and physical symptoms. Work \& Stress, 25(1), 1-22. https://doi.org/10.1080/02678373.2011.569175

Oshio, T., Inoue, A., \& Tsutsumi, A. (2018). Associations among job demands and resources, work engagement, and psychological distress: Fixed-effects model analysis in Japan. Journal of Occupational Health. https://doi.org/10.1539/joh.2017-0293-OA

Perrewé, P. L., Zellars, K. L., Ferris, G. R., Rossi, A. M., Kacmar, C. J., \& Ralston, D. A. (2004). Neutralizing job stressors: Political skill as an antidote to the dysfunctional consequences of role conflict. Academy of Management Journal, 47(1), 141-152. https://doi.org/10.2307/20159566

Sato, K., Kuroda, S., \& Owan, H. (2020). Mental health effects of long work hours, night and weekend work, and short rest periods. Social Science \& Medicine, 246, 112774. https://doi.org/10.1016/j. socscimed.2019.112774

Schaubroeck, J., Ganster, D. C., Sime, W. E., \& Ditman, D. (1993). A field experiment testing supervisory role clarification. Personnel Psychology, 46(1), 1-25. https://doi.org/10.1111/j.1744-6570. 1993.tb00865.x

Sodeke-Gregson, E. A., Holttum, S., \& Billings, J. (2013). Compassion satisfaction, burnout, and secondary traumatic stress in UK therapists who work with adult trauma clients. European Journal of Psychotraumatology, 4(1), 21869. https://doi.org/10.3402/ejpt.v4i0.21869

Steptoe, A., \& Wardle, J. (2005). Cardiovascular stress responsivity, body mass and abdominal adiposity. International Journal of Obesity, 29(11), 1329-1337. https://doi.org/10.1038/sj.ijo.0803011

The Lancet Global Health. (2020). Mental health matters. The Lancet Global Health, 8(11), e1352. https://doi.org/10.1016/S2214-109X(20)30432-0

Publisher's Note Springer Nature remains neutral with regard to jurisdictional claims in published maps and institutional affiliations. 